\title{
Preventive effect of Shuidouchi (short-term fermented soybean) on dextran sulfate sodium (DSS)-induced colitis in mice
}

\author{
Fang Tan ${ }^{1,2}$, Wei Liao ${ }^{1,2}$, and Xin Zhao ${ }^{1, *}$ \\ ${ }^{1}$ Chongqing Collaborative Innovation Center for Functional Food, Chongqing University of Education, Chongqing 400067, China \\ ${ }^{2}$ Department of Public Health, Our Lady of Fatima University, Valenzuela 838, Philippines
}

\begin{abstract}
In this study, mice colitis model was induced by dextran sodium sulfate (DSS), and the preventive effect of Shuidouchi on colitis was observed. The mice were divided into normal group, model group, low-content Shuidouchi feeding group, high-content Shuidouchi feeding group and sulfasalazine group. Serum and colon tissues of mice were detected by endothelin-1 (ET-1), somatostatin (SS), substance $\mathrm{P}$ (SP), vasoactive intestinal peptide (VIP), myeloperoxidase (MPO), glutathione (GSH), malondialdehyde (MDA), superoxide dismutase (SOD), interleukin-2 (IL-2), interleukin-10 (IL-10) kits. The results showed that compared with the model group, the feeding of Shuidouchi could significantly increase the length of colon and the ratio of colon weight to colon length in colitis mice $(p<0.05)$. By feeding Shuidouchi, the serum levels of ET, SP, IL-10 were decreased and SS, VIP, IL-2 were increased in mice with colitis. Detection of colon tissue in mice showed that Shuidouchi could significantly increase the levels of GSH, SOD and decrease the MPO, MDA levels in colitis mice $(p<0.05)$. It can be seen from this that Shuidouchi has a good preventive effect on colitis.
\end{abstract}

\section{Introduction}

Soybean sauce is a kind of Brewing Seasoning food in southwest China. It can be eaten directly and used in cooking [1]. Shuidouchi (Fig. 1) is a nutritious soybean product produced by fermentation of soybean. Its production process is simple. In addition to the direct production of household, enterprises can also carry out rapid production according to standardized technology [2]. In addition to its delicious taste and simple production, Shuidouchi also has many functions including antioxidant effects [3]. At the same time, traditional Chinese medicine also believes that Shuidouchi can alleviate inflammation and improve immunity [4]. Shuidouchi is rich in nutrients, including protein, vitamins and minerals. At the same time, Shuidouchi also contains soybean oligosaccharides. In addition to oligosaccharides in soybean raw materials, it also contains several new oligosaccharides produced by fermentation of soybean. Soybean oligosaccharides in Shuidouchi can improve digestive function. Shuidouchi can also improve the immunity of the body and reduce the toxic substances produced in the intestinal tract, so as to prevent intestinal diseases [5].

Ulcerative colitis (UC) is an inflammatory bowel disease with high incidence. It is a common method to study the effect and mechanism of food on UC through animal models [6]. Among them, sodium dextran sulfate (DSS) model can form ulcerative colitis similar to clinical manifestations, which is the most ideal ulcerative colitis model [7]. Intestinal mucosal permeability will change when intestinal inflammation gradually occurs. Intestinal mucosal permeability will also increase significantly when inflammation intensifies $[8,9]$. Nearly $95 \%$ of Chinese suffer from intestinal diseases, which seriously affect their health and quality of life. Colitis is one of the most important intestinal diseases, which poses a considerable risk to human health [10].

In this study, Shuidouchi purchased from Chongqing market in China was used as the research object to observe its inhibitory effect on DSS-induced colitis. The effects of Shuidouchi on experimental animals with colitis were detected by molecular biological methods, and the preventive effect of Shuidouchi on DSS-induced colitis was verified. The theoretical basis for further study of Shuidouchi was accumulated.

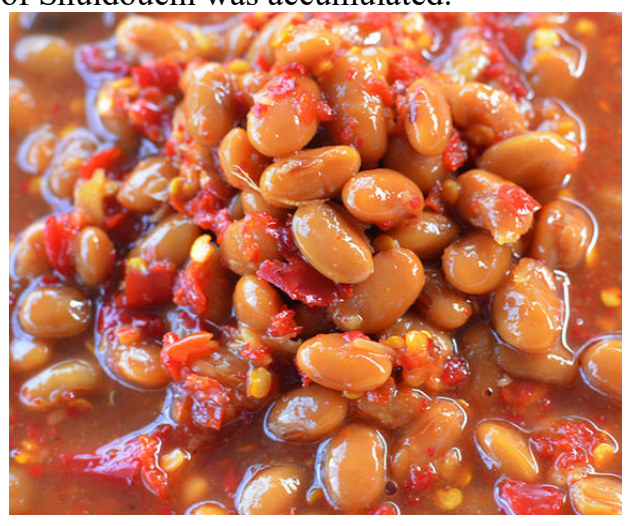

Fig. 1. Appearance of Shuidouchi.

\footnotetext{
* Corresponding author: zhaoxin@cque.edu.cn
} 


\section{Materials and Methods}

\subsection{Preparation of Shuidouchi feed}

The commercially available Shuidouchi was frozendried and then powdered. The powdered Shuidouchi was added into the feed of mice to make the feed containing $5 \%$ and $10 \%$ Shuidouchi.

\subsection{Experiment mice}

Seven-week-old male C57BL/6J mice were purchased from the Laboratory Animal Center of Chongqing Medical University (License No. SYXK (Chongqing) 2017-0001). The mice were fed at room temperature $(25 \pm 2)^{\circ} \mathrm{C}$ and relative humidity $(50 \pm 5 \%)$ and kept in the feeding environment to regulate light/darkness every 12 h.

\subsection{Experiment mice}

Seven-week-old male C57BL/6J mice were purchased from the Laboratory Animal Center of Chongqing Medical University (License No. SYXK (Chongqing) 2017-0001).

\subsection{Animal experiment}

Mice were divided into five groups: normal group, model group, low-content Shuidouchi feeding group (Shuidouchi-L group), high-content Shuidouchi feeding group (Shuidouchi-H group) and sulfasalazine group (positive control group). During the experimental period of 5 weeks, normal mice were given free drinking water and diet, and $0.2 \mathrm{~mL}$ normal saline was administered daily. Except normal mice, other mice in each group were given $2 \%$ and $4 \%(\mathrm{w} / \mathrm{v})$ DSS solution at the $3 \mathrm{rd}$ and 5th weeks, respectively. Mice in Shuidouchi-L and Shuidouchi-H groups were fed diets containing 5\% and $10 \%$ soybean sauce; mice in sulfasalazine group were fed with sulfasalazine at a daily concentration of 20 $\mathrm{mg} / \mathrm{kg} \mathrm{b.w}$, in addition to the free intake of drinking water and diet [11]. After 5 weeks, the mice were killed by neck-amputation, then the colon quality and length were measured, and the blood and colon tissue were taken for use.

\subsection{Determination of serum ET-1, SS, SP and VIP levels in mice}

The plasma of mice was centrifuged at $4500 \mathrm{r} / \mathrm{min}$ for 15 min, the supernatant was separated and the serum was got. Then the levels of ET-1, SS, SP and VIP in serum were determined by kits (Nanjing Jiancheng Bioengineering Institute, Nanjing City, China).

\subsection{Determination of serum IL-2 and IL-10 cytokine levels in mice}

The plasma of mice was centrifuged at $4500 \mathrm{r} / \mathrm{min}$ for 15 min, the supernatant was separated and the serum was got. Then the cytokine levels of IL-2 and IL-10 in serum were determined by kits (Abcam, Cambridge, MA, USA).

\subsection{Determination of MPO, SOD activities and GSH, MDA contents in colon tissue of mice}

The colon tissue was homogenized by ultrasound after mixing with saline at a mass ratio of 1:9. The activities of MPO, SOD and the contents of GSH, MDA in colon tissue were determined by kits (Nanjing Jiancheng Bioengineering Institute, Nanjing City, China).

\subsection{Data analysis}

The results of the three experiments were averaged, and then the one-way ANOVA method was used to analyze whether the results of each group had significant differences at the level of $p<0.05$. Different letters represented significant differences among the groups.

\section{Results}

\subsection{Effect of Shuidouchi on colon of mice}

After DSS induced colitis, mice suffered from fecal blood and weight loss. At the same time, the length of colon became shorter and enlarged after dissection. It was judged that the model was successful. The results showed that the colon length of model mice was the shortest, and that of normal mice was the longest. Meanwhile, the colon weight/colon length of model mice was the lowest, and that of normal mice was the highest (Table 1). The colon length and colon weight /colon length of Shuidouchi-H group were higher than those of model group and slightly lower than those of sulfasalazine group.

Table 1. Colon length and colon weight/colon length of each group mice.

\begin{tabular}{|c|c|c|}
\hline Group & Colon length $(\mathrm{cm})$ & $\begin{array}{c}\text { Colon weight/ Colon } \\
\text { length }(\mathrm{mg} / \mathrm{cm})\end{array}$ \\
\hline Normal & $9.2 \pm 0.4^{\mathrm{a}}$ & $44.1 \pm 3.3^{\mathrm{a}}$ \\
\hline Model & $3.4 \pm 0.4^{\mathrm{d}}$ & $16.3 \pm 2.6^{\mathrm{d}}$ \\
\hline Shuidouchi-L & $4.8 \pm 0.4^{\mathrm{c}}$ & $26.6 \pm 3.0^{\mathrm{c}}$ \\
\hline Shuidouchi-H & $6.9 \pm 0.6^{\mathrm{b}}$ & $35.1 \pm 3.1^{\mathrm{b}}$ \\
\hline Sulfasalazine & $7.6 \pm 0.5^{\mathrm{b}}$ & $36.5 \pm 2.9^{\mathrm{b}}$ \\
\hline
\end{tabular}

3.2 Effects of Shuidouchi on serum ET-1, SS, SP and VIP levels in mice

Table 2 showed that the serum levels of SS and VIP in normal mice were higher than those in other groups, 
while the levels of ET-1 were lower than those in other groups. In model mice, the serum levels of ET-1 and SP were the highest, while the serum levels of SS and VIP were the lowest. Compared with the model group, Shuidouchi could significantly increase the levels of SS and VIP in serum of mice with colitis $(p<0.05)$ and significantly reduce the levels of ET-1 and SP. The effect of high content Shuidouchi (Shuidouchi-H) was better, which was close to that of sulfasalazine group.

Table 2. ET-1, SS, SP and VIP serum levels of each group mice.

\begin{tabular}{|c|c|c|c|c|}
\hline Group & $\begin{array}{c}\text { ET-1 } \\
(\mathrm{pg} / \mathrm{mL})\end{array}$ & $\begin{array}{c}\text { SS } \\
(\mathrm{pg} / \mathrm{mL})\end{array}$ & $\begin{array}{c}\text { SP } \\
(\mathrm{pg} / \mathrm{mL})\end{array}$ & $\begin{array}{c}\text { VIP } \\
(\mathrm{pg} / \mathrm{mL})\end{array}$ \\
\hline Normal & $6.42 \pm 0.16^{\mathrm{e}}$ & $54.33 \pm 3.69^{\mathrm{a}}$ & $40.80 \pm 2.03^{\mathrm{e}}$ & $63.89 \pm 3.52^{\mathrm{a}}$ \\
\hline Model & $19.03 \pm 0.39^{\mathrm{a}}$ & $26.81 \pm 2.79^{\mathrm{e}}$ & $67.26 \pm 2.15^{\mathrm{a}}$ & $28.48 \pm 2.25^{\mathrm{e}}$ \\
\hline Shuidouchi-L & $14.69 \pm 0.33^{\mathrm{d}}$ & $32.02 \pm 2.86^{\mathrm{d}}$ & $58.36 \pm 2.20^{\mathrm{d}}$ & $40.37 \pm 1.92^{\mathrm{d}}$ \\
\hline Shuidouchi-H & $9.66 \pm 0.29^{\mathrm{c}}$ & $40.36 \pm 1.89^{\mathrm{c}}$ & $51.02 \pm 2.01^{\mathrm{c}}$ & $50.29 \pm 2.01^{\mathrm{c}}$ \\
\hline Sulfasalazine & $8.83 \pm 0.31^{\mathrm{b}}$ & $44.31 \pm 2.13^{\mathrm{b}}$ & $45.74 \pm 2.12^{\mathrm{b}}$ & $56.33 \pm 2.08^{\mathrm{b}}$ \\
\hline
\end{tabular}

\subsection{Effects of Shuidouchi on serum IL-2 and IL- 10 cytokine levels in mice}

Table 3 showed that the IL-2 cytokine level in serum of mice in model group was significantly lower than that of other groups $(p<0.05)$. Under the effect of Shuidouchi, the IL-2 cytokine levels in serum of mice in Shuidouchi$\mathrm{H}$ and Shuidouchi-L groups were significantly increased, and the level of IL-2 under the effect of Shuidouchi-H was slightly lower than that of sulfasalazine. On the contrary, the IL-10 cytokine level in serum of mice in model group was the highest, and that of mice in normal group was the lowest. The level of IL-10 in mice treated with Shuidouchi-H was only lower than that in mice treated with sulfasalazine and normal group.

Table 3. IL-2 and IL-10 serum cytokine levels of each group mice.

\begin{tabular}{|c|c|c|}
\hline Group & IL-2 $(\mathrm{pg} / \mathrm{mL})$ & IL-10 $(\mathrm{pg} / \mathrm{mL})$ \\
\hline Normal & $209.36 \pm 22.06^{\mathrm{a}}$ & $121.77 \pm 15.86^{\mathrm{d}}$ \\
\hline Model & $66.03 \pm 12.89^{\mathrm{d}}$ & $759.61 \pm 38.72^{\mathrm{a}}$ \\
\hline Shuidouchi-L & $97.32 \pm 19.30^{\mathrm{c}}$ & $506.84 \pm 29.63^{\mathrm{b}}$ \\
\hline Shuidouchi-H & $162.07 \pm 20.85^{\mathrm{b}}$ & $287.63 \pm 28.39^{\mathrm{c}}$ \\
\hline Sulfasalazine & $171.69 \pm 22.43^{\mathrm{b}}$ & $263.25 \pm 25.37^{\mathrm{c}}$ \\
\hline
\end{tabular}

\subsection{Effects of Shuidouchi on MPO, SOD contents and GSH, MDA activities in colon tissue of mice}

Table 4 showed that the GSH content and SOD activity are the strongest, MPO activity and MDA content are the weakest in the normal group, maintaining normal oxidation level in vivo, and no free radicals damage the body. After DSS-induced colitis, GSH content and SOD activity decrease significantly $(p<0.05)$, while MPO activity and MDA content increase significantly $(p<$
$0.05)$. Shuidouchi and sulfasalazine could significantly $(p<0.05)$ inhibit the decrease of GSH content, SOD activity and the increase of MPO activity and MDA content caused by DSS. At the same time, the effects of Shuidouchi-H were stronger than Shuidouchi-L.

Table 4. MPO, SOD activities and GSH, MDA contents in colon tissue of each group mice.

\begin{tabular}{|c|c|c|c|c|}
\hline Group & $\begin{array}{c}\text { MPO } \\
(\mathrm{mU} / \mathrm{mg})\end{array}$ & $\begin{array}{c}\text { SOD } \\
(\mathrm{U} / \mathrm{mg})\end{array}$ & $\begin{array}{c}\text { GSH } \\
(\mu \mathrm{mol} / \mathrm{mg})\end{array}$ & $\begin{array}{c}\text { MDA } \\
(\mathrm{nmol} / \mathrm{mg})\end{array}$ \\
\hline Normal & $5.21 \pm 0.14^{\mathrm{e}}$ & $91.52 \pm 4.66^{\mathrm{a}}$ & $7.88 \pm 0.45^{\mathrm{a}}$ & $0.22 \pm 0.02^{\mathrm{e}}$ \\
\hline Model & $28.93 \pm 2.65^{\mathrm{a}}$ & $25.37 \pm 3.03^{\mathrm{e}}$ & $2.61 \pm 0.27^{\mathrm{e}}$ & $1.74 \pm 0.22^{\mathrm{a}}$ \\
\hline Shuidouchi-L & $18.36 \pm 2.03^{\mathrm{b}}$ & $42.61 \pm 3.38^{\mathrm{d}}$ & $4.33 \pm 0.25^{\mathrm{d}}$ & $0.97 \pm 0.16^{\mathrm{b}}$ \\
\hline Shuidouchi-H & $11.06 \pm 1.66^{\mathrm{c}}$ & $64.52 \pm 3.62^{\mathrm{c}}$ & $5.67 \pm 0.21^{\mathrm{c}}$ & $0.51 \pm 0.06^{\mathrm{c}}$ \\
\hline Sulfasalazine & $8.92 \pm 1.58^{\mathrm{b}}$ & $76.18 \pm 3.05^{\mathrm{b}}$ & $6.27 \pm 0.22^{\mathrm{b}}$ & $0.37 \pm 0.04^{\mathrm{b}}$ \\
\hline
\end{tabular}

\section{Discussion}

The study confirmed that the colon quality and length of DSS-induced colitis mice were different from those of normal mice. In summary of previous studies, the ratio of colon weight to colon length could be used as an important criterion for evaluating the degree of experimental ulcerative colitis. The colon length of ulcerative colitis mice was lower than that of normal mice. At the same time, colon weight /colon length was lower than that of normal mice [12]. It can be concluded that Shuidouchi could significantly alleviate the decrease of colon length and colon weight/colon length ratio caused by DSS-induced colitis $(p<0.05)$, and the effect was similar to that of sulfasalazine, a drug of $20 \mathrm{mg} / \mathrm{kg}$ b.w.

Studies have shown that endothelin vasoconstriction can cause colonic mucosal erosion, even ulceration, can aggravate colitis $[13,14]$. SS can alleviate gastrointestinal inflammation by inhibiting the secretion of gastrointestinal juice such as gastric acid. The decrease of SS will aggravate the secretion of gastrointestinal juice and aggravate colitis [15]. Substance $P$ can regulate the nervous system and immune system, and the accumulation of substance $\mathrm{P}$ can aggravate the degree of colitis [14]. Meanwhile, excessive substance $\mathrm{P}$ can induce colitis, which can be alleviated by antagonizing substance $\mathrm{P}$ in animals [16]. VIP can inhibit the transcription of iNOS in the body, avoid excessive iNOS transforming into NO in colon tissue, which leads to damage of intestinal mucosa, and control the immune system disorder caused by colitis [15-17]. In this study, Shuidouchi could inhibit ulcerative colitis by inhibiting ET, SP levels and increasing SS and VIP levels.

IL-2 is a cytokine secreted by Th2 cells, which is directly related to UC. Th2 cells mediate immune response to affect UC. IL-2 plays a role in inhibiting inflammation by affecting Th2 cells and reducing the degree of UC $[18,19]$. IL-10 is a cytokine secreted by Treg cells with immunosuppressive effect and can promote the development of colitis [20]. Shuidouchi could increase the level of IL-2 and decrease the level of 
IL-10, and alleviate colitis by regulating the body's immune system.

After inflammation, the aggregation of neutrophils began to decrease, and a large number of neutrophils flowed into the tissues, resulting in a significant increase in MPO activity. At the same time, a large number of free radicals, such as ROS and RNS, accumulate, further damage and toxicity of colonic tissue, aggravating colitis [21]. After the occurrence of colitis, the content of GSH and SOD activity in colonic tissues decreased significantly, while the peroxide product MDA increased significantly. It is confirmed that controlling the accumulation of free radicals in tissues and enhancing the activity of enzymes inhibiting oxidation can play a role in inhibiting colitis [22]. The results of this study also confirm that UC leads to the decrease of SOD activity and GSH content, while the increase of MPO activity and MDA content. Shuidouchi could significantly inhibit the oxidative stress response of UC to colon and inhibit colitis.

\section{Conclusion}

In this study, DSS-induced colitis model in mice was used to study the preventive effect of Shuidouchi on colitis in vivo. By observing the serum and colon tissues of mice, the results showed that compared with the model mice of colitis, Shuidouchi could inhibit the effect of colitis on mice, alleviate colitis, and make the indexes of mice body change to normal state. At the same time, the content of Shuidouchi was positively correlated with the preventive effect of colitis, and the effect of high content Shuidouchi was stronger. It can be seen that Shuidouchi is a kind of high-quality traditional food with the effect of inhibiting colitis, which needs further development and utilization.

\section{Acknowledgement}

This work was supported by the Funded Project of Young Backbone Teachers in Chongqing Colleges and Universities and the Program for Innovation Team Building at Institutions of Higher Education in Chongqing (CXTDX201601040), China.

\section{References}

1. X. Zhao, China Condiment 39, 24-27 (2014)

2. X, Zhao, G.J. Li, Sci. Technol. Food Ind. 34, 217220 (2014)

3. X. Feng, X. Zhao, Sci. Technol. Food Ind. 37, 338342 (2016)

4. X. Zhao, Q. Wang, Sci. Technol. Food Ind. 35, 346349 (2014)

5. H.Y. Jiang, F.J. Lv, J.X. Tai, Soybean Sci. 19, 160164 (2000)

6. H. Nong, X. Huang, World Chinese J. Dig. 22, 3245-3250 (2014)
7. H.Z. Wen, W.W. Hao, Jia, L, Z.P. Tang, World Chinese J. Dig. 19, 3666-3671 (2011)

8. T.S. Olson, B.K. Reuter, K.G-E. Scott, M.A. Morris, X.M. Wang, L.N. Hancock, T.L. Burcin, S.M. Cohn, P.B. Ernst, F. Cominelli, J.B. Meddings, K. Ley, T.T. Pizarro, J. Exp. Med. 203, 541-552 (2006)

9. M.C. Arrieta, K. Madsen, J. Doyle, J. Meddings, Gut 58, 41-48 (2008)

10. M.J. Zhao, H.Y. Cai, Z.L. Jiang, Y. Li, H. Zhang, F.Q. Feng, Food Sci. 39, 336-343 (2018)

11. X. Chen, X. Zhao, H. Wang, Z. Yang, J. Li, H. Suo, Nutrients 9, E545 (2017)

12. W. Strober, I.J. Fuss, R.S. Blumberg, Ann. Rev. Immunol. 20, 495-549 (2002)

13. Y.P. Zhu, S.N. Lin, S. Huang, Z.Q. Luo, J. Guangxi Univ. Chinese Med. 10, 10-12 (2007)

14. F.J. Yang, D.J. Zhong, Y. Yu, L. Pu, Hainan Med. J. 24, 1954-1655 (2013)

15. W.T. Liu, L. Wu, Tianjin, Med. J. 25, 231-232 (1997)

16. Z.M. Song, B.N. Shi, L. Zhou, China Continuing Med. Educ. 2014, 82-83 (2014)

17. Y.C. Dai, Z.P. Tang, Z.N. Wang, Y.L. Zhang, K. Li, X.Y. He, World Chinese J. Dig. 17, 253-258 (2009)

18. P. Alex, N.C. Zachos, T. Nguyen, L. Gonzales, T.E. Chen, L.S. Conklin, M. Centola, X.H. Li, Inflamm. Bowel. Dis. 15, 341-352 (2009)

19. K. Matsuoka, N. Inoue, T. Sato, S. Okamoto, T. Hisamatsu, Y. Kishi, A. Sakuraba, O. Hitotsumatsu, H. Ogata, K. Koganei, T. Fukushima, T. Kanai, M. Watanabe, H. Ishii, T. Hibi, Gut 53, 1303-1308 (2004)

20. W.J. Yue, Y. Liu, W. Xu, L. Dong, X.T. Luo, W.R. Jiang, X. Sun, L. Zhong, J. Liu, Fudan Univ. J. Med. Sci. 39, 454-459 (2012)

21. A. Mustafa, A. El-Medany, H.H. Hagar, G. ElMedany, Pharmacol. Res. 53, 324-330 (2006)

22. C. Fiocchi, Curr. Opin. Gastroenterol. 20, 309-310 (2004) 